\title{
FUNDAMENTAL INSIGHT ON DEVELOPING LOW DIELECTRIC CONSTANT POLYIMIDES
}

\author{
J.O. Simpson and A. K. St.Clair \\ NASA Langley Research Center \\ Hampton, VA 23681-0001
}

\begin{abstract}
Thermally stable, durable, insulative polyimides are in great demand for the fabrication of microelectronic devices. In this investigation dielectric and optical properties have been studied for several series of aromatic polyimides. The effect of polarizability, fluorine content, and free volume on dielectric constant was examined. In general, minimizing polarizability, maximizing free volume and fluorination all lowered dielectric constants in the polyimides studied.
\end{abstract}




\section{INTRODUCTION}

High performance polyimides are widely used in the microelectronics industry. Of utmost importance for these microelectronics applications is that the polyimide have a low dielectric constant. In electronics packaging, low dielectric materials minimize crosstalk and maximize signal propagation speed in devices. Hence the development of polyimides with increasingly lower dielectric constants has been the focus of several recent investigations [1-5].

Among the strategies used to lower dielectric constants in polyimides are: incorporating diamine and dianhydride reactants which minimize polarizability; (2) incorporating diamine and dianhydride reactants which impart a high degree of free volume; and (3) incorporating fluorine atoms into the molecular structure of the polyimide [6]. We have synthesized and characterized several series of aromatic polyimides to examine the effect of polarizability, free volume, and fluorine content on the dielectric properties of polyimides. The fundamental insight gained from these studies and others is reported herein.

\section{BACKGROUND}

\section{Polarizability}

Dielectric constants of polyimides, in general, are known to decrease gradually with increasing frequency. For example, Kapton $\mathrm{H}$ film $(25.4 \mu \mathrm{m})$ has a dielectric constant of approximately 3.5 at $1 \mathrm{kHz}$ and 3.3 at $10 \mathrm{MHz}$ [7]. This variation in dielectric constant is attributed to the frequency dependence of the polarization mechanisms which comprise the dielectric constant. The magnitude of the dielectric constant is dependent upon the ability of the polarizable units in a polymer to orient fast enough to keep up with the oscillations of an alternating electric field. As shown in Figure 1, the polarizable units are electronic, atomic and dipolar. At optical frequencies $\left(10^{14} \mathrm{~Hz}\right)$, only the lowest mass species, electrons, are efficiently polarized. At lower frequencies, atomic polarization of heavier, more slowly moving nuclei also contribute to the dielectric constant. Atomic polarization of induced dipoles 
such as a carbonyl group can occur in the infrared $\left(10^{12} \mathrm{~Hz}\right)$ or lower frequency regimes. Dipole polarization is the redistribution of charge when a group of atoms with a permanent dipole align in response to the electric field. In the solid state, alignment of permanent dipoles requires considerably more time than electronic or atomic polarization, occurring at microwave $\left(10^{9} \mathrm{~Hz}\right)$ or lower frequencies.

The polarizability $(\alpha)$ of each species is generally additive (i.e., $\alpha=\alpha_{\text {electronic }}+$ $\alpha_{\text {atomic }}+\alpha_{\text {dipolar }}$ ) and can be combined with the Clausius-Mossotti relationship to estimate the contribution of each polarization mode to the dielectric constant $(\varepsilon)$ as shown in equation (1) [11].

$$
\varepsilon=\varepsilon_{\text {electronic }}+\varepsilon_{\text {atomic }}+\varepsilon_{\text {dipolar }}
$$

At optical frequencies, where only electronic polarization occurs, the dielectric constant, $\varepsilon_{\infty}$, is related to the refractive index, $\mathrm{n}_{\text {ref, }}$, by Maxwell's identity.

$$
\varepsilon_{\infty}=\left(n_{\text {ref }}\right)^{2}
$$

A comparison of the $\varepsilon_{\infty}$ and the dielectric constant measured at frequencies lower than optical frequency can lead to a basic understanding of the influence of molecular structure on dielectric properties in polyimides.

\section{Free Volume}

A correlation of high free volume and low dielectric constant has been previously reported for polyimides [8-10]. In these investigations positron lifetime spectroscopy and group additivity methods were used to quantify free volume fractions. The introduction of free volume in a polymer decreases the number of polarizable groups per unit volume resulting in lower values for $\varepsilon_{\text {atomic }}$ and $\varepsilon_{\text {dipolar. }}$ The addition of pendant groups, flexible bridging units, and bulky groups which limit 
chain packing density have all been used to enhance free volume in polyimides and are used in this study to examine their effect on dielectric constant.

\section{Fluorine Content}

Although incorporation of fluorine into polyimides has been shown to lower dielectric constants, indiscriminate fluorine substitution may actually yield an undesired effect. Hougham et al. have shown that nonsymmetric substitution of fluorine for hydrogen increases the average magnitude of the dielectric constant by approximately 0.05 per substituted ring [11]. Symmetric substitution of fluorine does not increase the net dipole moment of the polymer and hence, does not increase the dielectric constant. In fact, in the same study Hougham et al. have shown that the dielectric constant decreases with symmetric fluorine substitution by a combination of lower electronic polarizability and larger free volume. In this study, symmetric and nonsymmetric fluorinated groups are used to elucidate the influence of fluorine content on dielectric constant.

\section{EXPERIMENTAL}

Chemical repeat units of the aromatic diamine and dianhydride monomers used to prepare the polymers of this investigation are shown in the accompanying tables. Pyromellitic dianhydride (PMDA), 3,3', 4,4'-benzophenone tetracarboxylic dianhydride (BTDA), and 2,2-bis(3,4-dicarboxyphenyl)hexafluoropropane dianhydride (6FDA), 4,4'-oxydianiline (4,4'-ODA), 3,3'-diaminodiphenylsulfone (DDS02) and 1,3bis(aminophenoxy)benzene (APB) were obtained from commercial sources. The other monomers were experimental materials obtained as follows: 4,4' oxdiphthalic anhydride (ODPA) and 1,4-bis(3,4-dicarboxyphenoxy)benzene dianhydride (HQDEA) from Occidental Chemical Corporation; 4,4'-bis(3,4-dicarboxyphenoxy) diphenyl sulfide dianhydride (BDSDA), an experimental material from General Electric Corporate R\&D Center; 3,3'-oxydianiline (3,3'-ODA) and 2,2-bis[4(3aminophenoxy)phenyl]hexafluoropropane (3-BDAF) from Mitsui Toatsu, Inc.; 2,2- 
bis[4(4-aminophenoxy)phenyl]hexafluoropropane (4-BDAF) from Ethyl Corporation and 2,2-bis(4-aminophenyl)hexafluoropropane (4,4'-6F) from Hoechst Celanese.

Polyamic acid precursor solutions were prepared by mixing equimolar portions of diamine and dianhydride at room temperature at $15 \%$ solids by weight in dimethylacetamide for 8-24 hours. Polymer films were prepared by casting the polyamic acid solutions onto glass plates in an enclosed dust-free chamber at $10 \%$ $\mathrm{RH}$. Polyamic acid films were converted to polyimide by heating one hour each at $100^{\circ}, 200^{\circ}$, and $300^{\circ} \mathrm{C}$ in forced air.

Dielectric measurements were performed on 1 mil $(25.4 \mu \mathrm{m})$ thick polyimide films by two methods. The gigahertz dielectric constant measurements were obtained using a Hewlett Packard 8510 Automated Network Analyzer over a frequency range of 8-12 GHz. The films were desiccated overnight prior to measurement and were run at room temperature at $25-35 \% \mathrm{RH}$. The reported dielectric constants are quoted at 10 $\mathrm{GHz}$ and are accurate to \pm 0.03 . The megahertz dielectric constant measurements were obtained using a fixed gap parallel plate capacitor consisting of two $2.54 \mathrm{~cm}$ square aluminum plates mounted on glass plates. A spacer was used to obtain a capacitor with a fixed gap spacing no more than 20 microns greater than the sample thickness. Using the impedance measurements with and without the film and the film thickness, the dielectric constant of the sample was calculated at $1 \mathrm{MHz}$ with an accuracy of \pm 0.12 .

Refractive index measurements were obtained at ambient temperature by the Becke Line method [12] using a polarizing microscope and standard immersion liquids obtained from R.P. Cargille Labs.

\section{RESULTS AND DISCUSSION}

\section{Polarizability}

Table I lists the measured dielectric constants and $\varepsilon_{\infty}$ as calculated from the refractive indices. The optical frequency dielectric constant values are equal within 
experimental accuracy to the dielectric constants measured at $10 \mathrm{GHz}$ except for the polyimide which contains BTDA. The BTDA dianhydride contains the polar carbonyl linkage which contributes to the large difference between $\varepsilon_{\infty}$ and $\varepsilon(@ 10 \mathrm{GHz})$. While the $-\mathrm{CF}_{3}$ pendant groups in $6 \mathrm{FDA}+4-\mathrm{BDAF}$ combine to give a net resultant dipole, the polarization of this dipole is essentially frozen out at $10 \mathrm{GHz}$.

Dielectric constants measured at $10 \mathrm{GHz}$ and $1 \mathrm{MHz}$ are plotted against the optical frequency dielectric constant in Figure 2. Substantial increases in the dielectric constant are observed as the measurement frequency is decreased from $10 \mathrm{GHz}$ to 1 $\mathrm{MHz}$. This increase is attributed to the polarization of induced and permanent dipoles as the time scale of the dielectric constant measurement is extended. As illustrated in Figure 1, dipole alignment which is not detectable at $10 \mathrm{GHz}$ adds to the dielectric response at $1 \mathrm{MHz}$.

\section{Free Volume}

The introduction of free volume in aromatic polyimides can be accomplished by using reactants which result in inefficient chain packing in the solid state. Among the methods for achieving decreased chain packing density are incorporating substituents with ortho and meta linkages along the polymer backbone; incorporating flexible bridging units in the backbone; and adding pendant groups along the polymer backbone. Table II presents dielectric constant measurements for a series of oxydialine (ODA) containing polymers in which the para and meta isomers, 4,4'-ODA and $3,3^{\prime}-O D A$, have been systematically varied to illustrate the effect of incorporating "kinks" in the polymer backbone on the dielectric constant. In each case meta isomerism lowers the dielectric constant as compared to the corresponding polymers with para isomerism.

A large reduction in dielectric constant is observed with the use of the 6FDA dianhydride. The 6FDA + 3,3'-ODA polymer has a large free volume due to the pendant $-\mathrm{CF}_{3}$ groups and the meta catenation of the diamine. 
Free volume fractions have been quantified for three of the polymers studied by positron lifetime spectroscopy as described by Eftekhari et.al. [13]. As shown in Table III, the free volume fraction is larger for ODPA + 3,3'-ODA than ODPA + 4,4-ODA. The "kink" in the 3,3'-ODA diamine inhibits close packing of the polymer chains resulting in a larger free volume. Likewise, the incorporation of bulky trifluoromethyl pendant groups in the 6FDA dianhydride sterically hinders packing and enlarges the free volume in 6FDA relative to the ether linkage in ODPA. Increased free volume correlates with decreased dielectric constants for these polymers.

\section{Fluorine Content}

Dielectric constant as function of fluorine content is shown by the filled circle symbols ( $)$ in Figure 3 for the polyimides listed in Table I. The dielectric constant decreases almost linearly with increasing weight percent fluorine. The exception to this trend is for BTDA + BDAF polyimide for which the dielectric constant is slightly higher due to the polarization of the carbonyl group. The dielectric constant is minimized for 6FDA + 4-BDAF in which both the dianhydride and diamine portions of the polymer contain trifluoromethyl groups. Fluorine substitution lowers the dielectric constant by a combination of mechanisms. The incorporation of the bulky $-\mathrm{CF}_{3}$ group prohibits close packing of the polymer chains and reduces interchain charge transfer of the highly polar dianhydride groups [14]. In addition, the large fluorine atoms increase the free volume fraction in the polymer essentially reducing the number of polarizable groups in a unit volume. Fluorine substitution also lowers the electronic polarization in the polymer due to the large electronegativity of the C-F bond.

The two trifluoromethyl groups in these polymers result in a net dipole which can produce dipole polarization if enough molecular mobility exists. However, for the measurement conditions (i.e. room temperature and high frequency), the effect of polarization associated with this dipole on the dielectric constant is not as pronounced as it is for polymers that contain a single, nonsymmetric polar group. Nonsymmetric 
substitution of fluorine did not necessarily result in a lowering of the dielectric constant with increasing fluorine content. As shown in Table IV, the DABTF and DASP diamines contain a single trifluoromethyl and pentafluorosulfanyl group, respectively, whereas the 3-BDAF and 4,4'6F diamines contain two trifluoromethyl groups. The synthesis of the DABTF and DASP containing polyimides is described elsewhere [15, 16]. The filled square symbols ( $\square$ ) in Figure 3 illustrate the effect of weight percent fluorine on dielectric constant for these polyimides. The nonsymmetric fluorinated diamines both yield polyimides with higher dielectric constants than those containing symmetric trifluoromethyl groups. This is possibly due to the large dipole moments of the $\mathrm{C}-\mathrm{F}$ and S-F bonds. Each of the polymers with dielectric constants well above the linear fit in Figure 3 (BTDA, DABTF, and DASP) contain asymmetric polarizable groups. Even though the 6FDA + DASP polyimide has the highest fluorine content, its dielectric constant is not the lowest. It is important to note that

\section{CONCLUSIONS}

In this investigation we report structure/property data on the effect of polarizability, free volume and fluorine content on dielectric constants for several aromatic polyimides. This type of analysis is crucial for making further improvements in the development of insulative polymers. Minimizing polarizability, maximizing free volume and fluorination all lowered dielectric constants in the polyimides studied. Polarizability is the primary variable influencing dielectric constants whereas free volume and fluorine content are secondary variables which can alter a polymer's polarizability. Enhanced free volume lowers polarization by decreasing the number of polarizable groups per unit volume. Fluorination increases free volume, lowers electronic polarization and can either increase or have no effect on dipole polarization depending on whether the fluorination is asymmetric or symmetric. 


\section{ACKNOWLEDGMENTS}

The authors gratefully acknowledge the technical support of Mr. Mason Proctor and Mr. Burt Emerson of NASA Langley Research Center for polyimide film synthesis and measurement of dielectric properties. 


\section{REFERENCES}

1. F.W. Mercer and T.D. Goodman, High Performance Polymers, 3 (1991) 297.

2. A.C. Misra, G. Tesoro, G. Hougham, and S.M. Pendharkar, Polymer, 33(5), 1078 (1992).

3. Y.S. Negi, Y. Suzuki, I. Kawamura, et.al., J. Polym. Sci. Part A: Polym. Chem., 30 (1992) 2281.

4. R. Reuter, H. Franke, and C. Feger, Applied Optics, 27(21), 4565 (1988).

5. G. Hougham, G. Tesoro and J. Shaw, Macromolecules, 27 (1994) 3642.

6. A.K. St. Clair, T.L. St. Clair and W.P. Winfree, US Patent No. $5,338,826$ (16 August 1994).

7. "Kapton Polyimide Film-Summary of Properties", published by DuPont Co., Polymer Products Department, Industrial Films Division, Wilmington, DE 1989.

8. J.J. Singh, T.L. St.Clair, W.H. Holt, and W. Mock, NASA Tech. Memo. No. 86431 (1985).

9. $\quad$ Eftekhari, A., A.K. St.Clair, D.M. Stoakley, S. Kuppa, and J.J. Singh, J. Polym. Mater. Sci. Eng., 66 (1992) 279.

10. G. Hougham, G. Tesoro and A. Viehbeck, Macromolecules, 29 (1996) 3453.

11. G. Hougham, G. Tesoro, A. Viehbeck and J.D. Chapple-Sokol, Macromolecules, 27 (1994) 5964.

12. R.C. Faust, Proc. Phys. Soc., 68B (1955) 1081.

13. A. Eftekhari, A.K. St. Clair, D.M. Stoakley, S. Kuppa, J.J. Singh, Polym. Mater. Sci. Eng, 66 (1992) 279.

14. A.K. St. Clair, T.L. St. Clair, and W.P. Winfree, ACS Polym. Matls.: Sci. and Eng., 59 (1988) 28.

15. M.K. Gerber, J.R. Pratt, A.K. St.Clair and T.L. St.Clair, Proc. Am. Chem. Soc., Polymer Div., 31 (1990) 340.

16. A.K. St.Clair, T.L. St.Clair and J.S. Thrasher, Proc. Am. Chem. Soc., Polymer Div., 34 (1993) 385. 
Table I. Chemical repeat unit and dielectric properties for 4-BDAF containing polyimides.<smiles></smiles>

\begin{tabular}{|c|c|c|c|c|c|}
\hline Dianhydride & Structure (Ar) & $n_{\text {ref }}$ & $\varepsilon_{\infty}$ & $\varepsilon, \mathrm{GHz}$ & $\varepsilon, \mathrm{MHz}$ \\
\hline BDSDA & & 1.64 & 2.69 & 2.69 & 3.08 \\
\hline BTDA & & 1.62 & 2.62 & 2.74 & 3.03 \\
\hline ODPA & & 1.62 & 2.62 & 2.68 & 3.08 \\
\hline PMDA & & 1.62 & 2.62 & 2.63 & 2.93 \\
\hline 6FDA & & 1.58 & 2.50 & 2.50 & 2.77 \\
\hline
\end{tabular}


Table II. Dielectric properties of ODA containing polyimides.

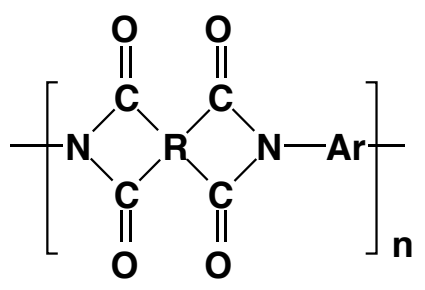

\begin{tabular}{|c|c|c|c|}
\hline Polymer & Dianhydride $(\mathrm{R})$ & Diamine (Ar) & $\varepsilon(10 \mathrm{GHz})$ \\
\hline $\begin{array}{l}\text { PMDA + 4, 4'-ODA } \\
\text { (Kapton) }\end{array}$ & & & 3.22 \\
\hline PMDA + 3, 3'-ODA & & & 2.84 \\
\hline BTDA + 4, 4'-ODA & & & 3.15 \\
\hline BTDA + 3, 3'-ODA & & & 3.09 \\
\hline ODPA + 4, 4'-ODA & & & 3.07 \\
\hline ODPA + 3, 3'-ODA & & & 2.99 \\
\hline HQDEA + 4, 4'-ODA & & & 3.02 \\
\hline HQDEA + 4, 4'-ODA & & & 2.88 \\
\hline $\mathrm{BDSDA}+4,4^{\prime}-\mathrm{ODA}$ & & & 2.97 \\
\hline $\operatorname{BDSDA}+3,3$ '-ODA & & & 2.95 \\
\hline $6 F D A+4,4^{\prime}-\mathrm{ODA}$ & & & 2.79 \\
\hline $6 F D A+3,3 '-O D A$ & & & 2.73 \\
\hline
\end{tabular}


Table III. Free volume fractions for polyimides.

\begin{tabular}{|c|c|c|}
\hline Polyimide & $\begin{array}{c}\text { Dielectric Constant } \\
(10 \mathrm{GHz})\end{array}$ & $\begin{array}{c}\text { Free Volume Fraction } \\
(\%)\end{array}$ \\
\hline ODPA + 4,4'-ODA & 3.07 & 0.58 \\
\hline ODPA + 3,3'-ODA & 2.99 & 0.62 \\
\hline 6FDA + 3,3'-ODA & 2.73 & 1.34 \\
\hline
\end{tabular}


Table IV. Chemical repeat unit, dielectric constant and fluorine content for 6FDA containing polyimides.

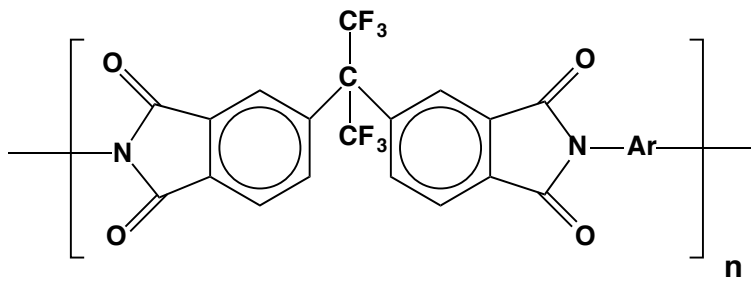

\begin{tabular}{|c|c|c|c|}
\hline Diamine & Structure (Ar) & $\begin{array}{c}\varepsilon \\
(10 \mathrm{GHz})\end{array}$ & $\begin{array}{l}\text { Weight \% } \\
\text { Fluorine }\end{array}$ \\
\hline DABTF & & 2.58 & 29 \\
\hline DASP & & 2.51 & 33 \\
\hline 3-BDAF & & 2.40 & 25 \\
\hline $4,4^{\prime} 6 \mathrm{~F}$ & & 2.39 & 31 \\
\hline
\end{tabular}




\section{LIST OF FIGURE CAPTIONS}

Figure 1. Polarization phenomena which influence the dielectric constant.

Figure 2. Dielectric constants for 4-BDAF containing polyimides measured at three frequencies.

Figure 3. Dielectric constant as a function of fluorine content.

(- represent polyimides which contain 4-BDAF diamine as shown in Table I)

(匹 represent polyimides which contain 6FDA dianhydride as shown in Table IV) 


\section{FIGURES}


No Electric Field:

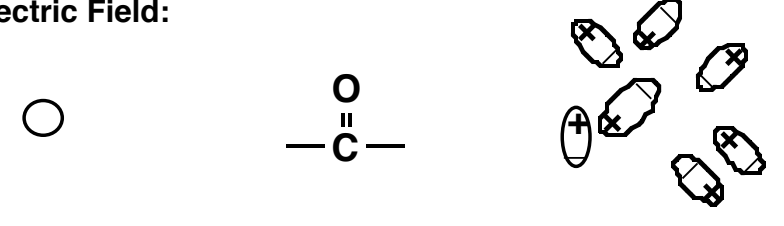

With Electric Field:
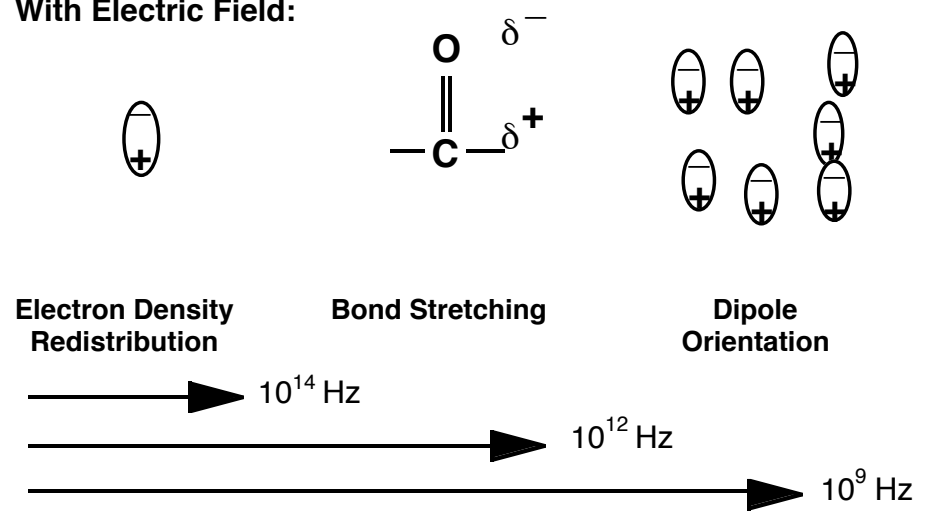


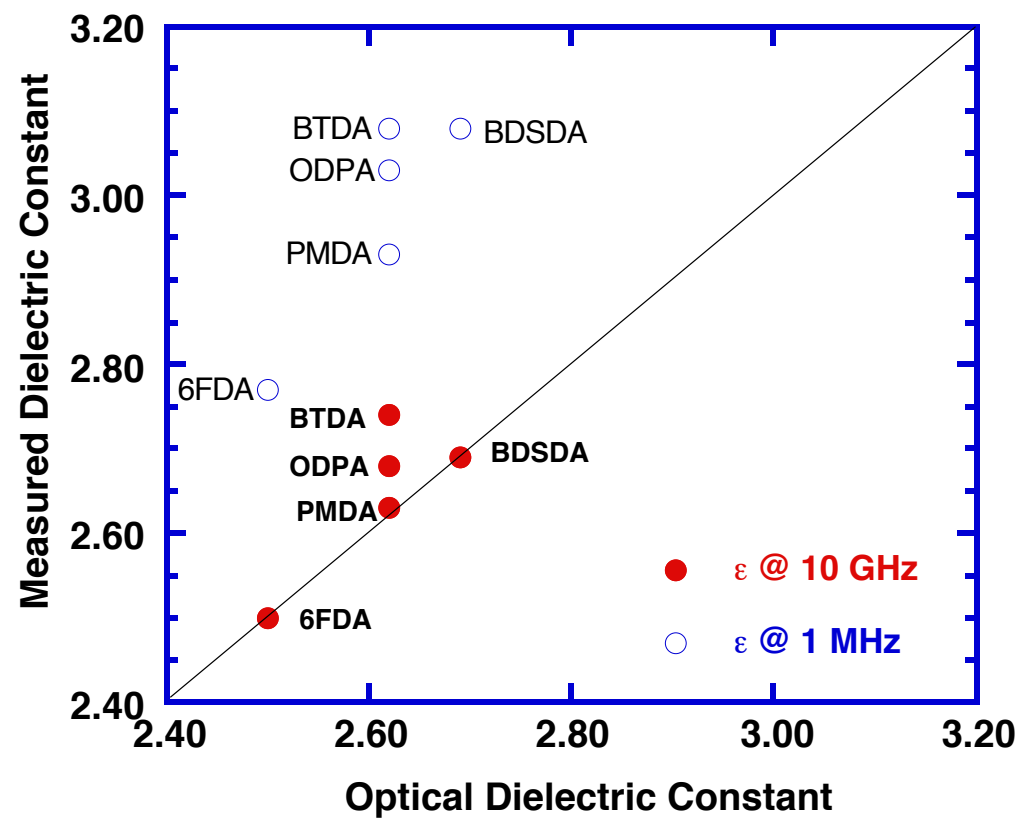




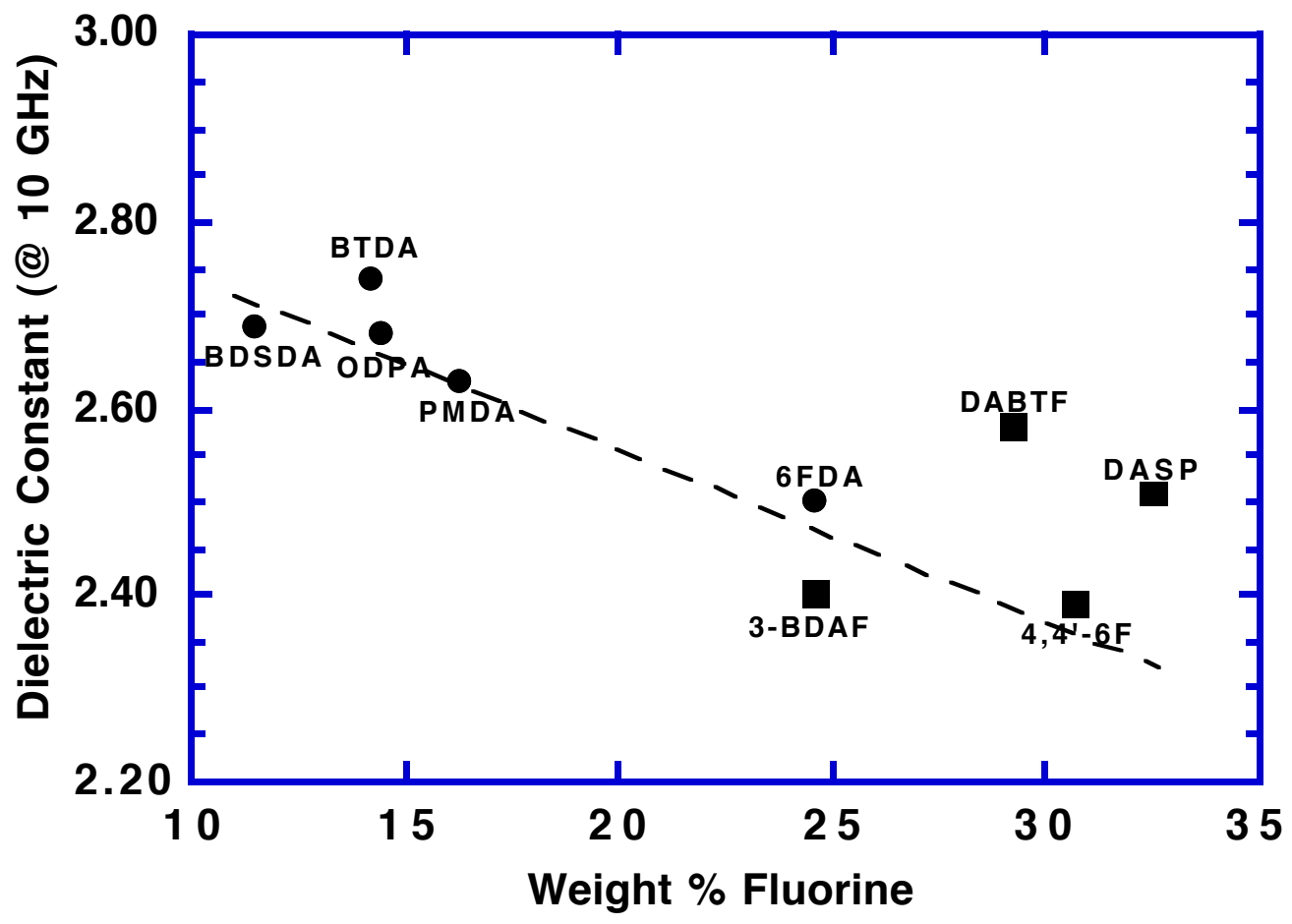

